WellBeing International

WBI Studies Repository

$5-1997$

\title{
The Scientific Validity of Subjective Concepts in Models of Animal Welfare
}

Françoise Wemelsfelder

Scottish Agricultural College

Follow this and additional works at: https://www.wellbeingintlstudiesrepository.org/acwp_awap

Part of the Animal Studies Commons, Behavior and Ethology Commons, and the Comparative Psychology Commons

\section{Recommended Citation}

Wemelsfelder, F. (1997). The scientific validity of subjective concepts in models of animal welfare.

Applied Animal Behaviour Science, 53(1), 75-88.

This material is brought to you for free and open access by WellBeing International. It has been accepted for inclusion by an authorized administrator of the WBI Studies Repository. For more information, please contact wbisr-info@wellbeingintl.org.

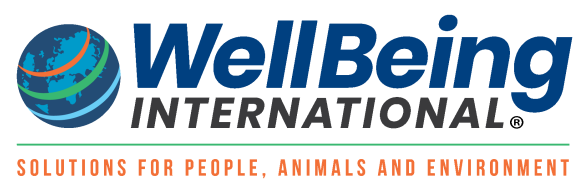




\title{
The Scientific Validity of Subjective Concepts in Models of Animal Welfare
}

\author{
Françoise Wemelsfelder \\ Scottish Agricultural College
}

\section{KEYWORDS}

subjective experience, awareness, welfare, attention, behavioural causation, qualitative measurement

\begin{abstract}
This paper takes a closer look at the subjectivity/objectivity relationship, as it plays a role in the science of animal welfare. It argues that subjective, experiential states in animals such as well-being and suffering are, contrary to what is often assumed, open to empirical observation and scientific assessment. The presumably purely private, inaccessible nature of such states is not an inherent property of these states, but derives from their misguided conception as 'causal objects' in mechanistic models of behaviour. This inevitably endows subjective experience with a 'hidden' status. However, subjective experience should be approached on its own conceptual grounds, i.e. as a perspective, in terms of 'what-it-is-like-to-be' a particular individual animal. Neither behaviour nor subjective experience then can be regarded as causal objects; they form an integrated, dynamic, expressive whole. The animal is perceived as an agent, whose perspective on a given situation is manifest in the way in which it interacts with and pays attention to that situation. In this framework, concepts of subjective experience such as enthusiasm, timidity. Fear or contentedness, may be defined as categories of 'attentional style'. Testing the scientific validity and reliability of such categories requires development of a qualitative methodology for the measurement of behaviour. Starting-points for such a method are put forward for discussion.
\end{abstract}

\section{Introduction}

Concepts of animal welfare such as well-being and suffering indicate that animals are capable of subjective, sentient experience (Dawkins, 1990; Duncan and Petherick, 1991; Bekoff, 1994). Scientists in the field of animal welfare seek to investigate the experience of animals as it arises under a variety of circumstances and housing conditions, in an unbiased and reliable way. In other words, the task at hand is to submit concepts referring to subjective experience to objective measurement and evaluation. Clearly, the way in which the terms 'subjective' and 'objective' are interpreted will have an important effect on the way problems of animal welfare are formulated, and on the direction in which answers are sought. A discussion dealing explicitly with the subjectivity/objectivity relationship seems therefore relevant.

The relationship between subjectivity and objectivity is by no means straightforward; different interpretations have been proposed by philosophers and other theoreticians over the centuries. Current 
models of animal behaviour and welfare are to an important extent still based on dualistic principles, as conceived by the 17th century French philosopher Descartes. Descartes was a rationalist of the purest form, believing that knowledge of the world must be formulated in strictly logical and mathematical terms. He did not see physical bodies in the world, including animals, as having an existence beyond that of the law-like, mechanical motions described by mathematics. To human beings, however, he granted an inner awareness which, due to its communion with an all-knowing God, allowed them reflection upon, and freedom from, mechanical motion. Thus, a dualistic view conceives of subjective awareness as 'not really being part' of the objective, observable universe. Inevitably, then, it acquires the status of an internal, hidden and private phenomenon. Modern scientists of course mostly no longer accept Descartes' view of subjective awareness as God's gift to human kind. They regard it as an emergent property of complex neural organisation, a view which may well include a variety of animal species. However, the idea that subjective experience is exclusively private, and not liable to objective measurement has survived the centuries intact. Assessment of phenomena deemed 'subjective' is at best considered inferential, or at worst, as unwarranted projection of human values. Fear of anthropomorphic projection makes scientists generally reluctant to explicitly discuss their behavioural observations in terms of subjective well-being or suffering.

In response to this situation, various scientists have proposed that careful and detailed study of behaviour (e.g. communicative, or choice behaviour) provides the best possible access to any underlying inner experience, and should, despite its indirectness, be given respectable scientific status (Dawkins, 1990, 1993; Duncan and Petherick, 1991; Griffin, 1992; Bekoff, 1994). Others have argued that the indirectness of observations on an animal's experience presents no special problem, in that all scientific observation is theory-laden, and in that sense indirect (Rushen, 1984/85). These are important and constructive approaches, and have led to various kinds of scientific progress (Bekoff, 1994). Yet, given our current view of subjectivity and objectivity as mutually exclusive principles, the danger is great that judgements of well-being and suffering will continue to fundamentally be seen as anthropomorphic projections, rather than as conclusions based on hard scientific evidence. This will be especially so in the case of conflicting interests. The question is whether the indirectness of the study of subjective experience in animals must be accepted at face value, or whether further examination of the subjectivity/objectivity relationship may reveal other possible approaches.

This paper examines the proposition that concepts denoting subjective experience in animals are in fact open to empirical investigation, and as such are liable to objective analysis. This requires that, first, the dualistic model of the subjectivity/objectivity relationship be put to closer scrutiny. It is argued that this model inevitably misconstrues subjective experience as a 'difficult-to-deal-with' object. The alternative is to acknowledge that a purely mechanistic conception of scientific objectivity (as inspired by Cartesian dualism) is too narrow, and that subjective phenomena require a level of description and analysis in their own right. The subject-status of animals can then be taken as a starting-point for models dealing with the experiential aspects of well-being and suffering. The question is whether, and how, such models can be submitted to systematic and reliable testing. In conclusion, suggestions towards an answer of this question are put forward for discussion.

\section{Animals as objects: an exclusively mechanistic view of behavior}

A dualistic view of the subjectivity/objectivity relationship equates objectivity with law-like, mechanistic organisation. Current scientific models of animal behaviour assume in accordance with this view that behaviour is, essentially, a complex mechanical system. This also applies to models which take into account the goal-directed nature of behaviour. Here, the postulation of more or less complex selfregulatory feedback mechanisms provides the conceptual link with the overall mechanistic paradigm (Staddon, 1983). Causation in mechanical systems is automatic, reactive, and, ultimately, deterministic; 
the system behaves strictly in accordance with the universal laws which govern the motion of physical objects. This does not however make mechanical systems easily predictable. Goal-oriented patterns of behaviour can be highly intricate and probabilistic, reflecting the system's ability to internally represent features of the environment on a variety of organisational levels. In this case, mechanical systems are frequently granted cognitive status. They are conceived as 'active' rather than as merely 'reactive' entities (Dickinson, 1985; Toates, this issue). However, the meaning of the term 'active' in this context should be evaluated with care. This term does indicate that the system is not a simple stimulus-bound device, yet it does not contradict the overall system's reactive causal status. Cognitive processes provide a more complex kind of stimulus-input than is the case in simple S-R relations, but causation in the behavioural system as a whole continues to be seen as a reactive trade-off process designed by natural selection (McFarland, 1989). In a formal causal sense, current models of behaviour (including cognitive ones) conceive of animals as physical objects.

If a mechanistic approach is taken as the norm for scientific objectivity, scientists seeking to develop an objective approach to animal welfare have no choice but to model an animal's experience in terms of reactive causation. That is, they must conceive of subjective experience as a causal factor in an otherwise mechanistic scheme of animal behaviour. To say that 'an animal runs away because it is afraid' is then taken to mean 'fear causes running', with the terms fear and running in two separate boxes and an arrow between them for causation. However, such a model presents the scientist with a 'catch-22' situation. Given its subjective nature, the experience of fear cannot be an observable cause within the mechanistic scheme. It therefore must be conceived as a hidden, internal cause. It subsequently is seen as an 'awareness', a mental state driving behaviour from 'within'. But the existence of hidden causes cannot be tested experimentally, and can therefore not be accepted as a scientific explanation. Thus, objectification of subjective phenomena within a mechanistic model appears to be self-defeating. Rather than providing these phenomena with scientific solidity, it tends to render them more elusive.

This problem stood out clearest in purely Cartesian models, but a cognitive approach, despite its reliance on neural science, does not solve or overcome it. The hypothesis that internal goal-related representations cause behaviour can be tested, but only in so far as cognition is regarded as a physical property of the brain (see above). As soon as cognition is linked to subjective awareness or feelings, as several authors propose (e.g. Duncan and Petherick, 1991), testing again becomes ambiguous and problematic. Alternative accounts, explaining observed patterns of behaviour in more or less complex mechanistic terms (the robot-simulation argument), will always be available. One can always say that the animal, robot-like, goes through the motions of a pain-response, but does not 'really feel' it. This dilemma is reflected, for example, in recent repudiations of proclaimed evidence of self-awareness in various primate species (Kennedy, 1992; Heyes, 1993, 1994). Recognition that subjective phenomena just do not fit into mechanistic schemes of explanation, then, is what drove behaviourists and early ethologists to remove these phenomena from the scientific arena altogether. In the words of the father of modem ethology, Niko Tinbergen: "Although...the ethologist does not want to deny the possible existence of subjective phenomena in animals, he claims that it is futile to present them as causes, since they cannot be observed by scientific methods" (Tinbergen, 1989, p. 5). This formal explanatory problem, as Van Rooijen $(1983,1991)$ has pointed out, has not lost its relevance for the science of animal welfare today.

The scientist's interest in subjective experience in animals is thus like Tantalus' torment: we can see it may be there, but we cannot get at it other than through indirect criteria. Yet the immunity of subjective concepts to empirical observation is not something inherent to such concepts; it only follows from a dualistic conception of the subjectivity/objectivity relationship. Dualism sets its own trap: by equating scientific objectivity with mechanism, it a priori transforms subjectivity into a causally ineffective byproduct. Little else can be done in this situation than declaring inner experience to be essentially 'private', 
accessible only through introspection and/or the study of behavioural analogy. However, the exclusive privateness of experience only holds if the mechanistic nature of behaviour is taken for granted without further consideration. This, as indicated above, implies adopting a strictly logical, mathematical conception of the universe as an absolute norm of reality. But it is hard to see how any sort of notion of subjectivity, human or animal, could ever fit into such a view. This stance reflects an ultimately objectivistic attitude towards the natural world, (perhaps dogmatically) assuming that the mechanistic perspective held by modem (western) science is the ultimately true one (e.g. Dennett, 1991).

However, questioning science in its current state will make for better and more responsible science (after Bekoff, 1994, p. 89). This is not to assert that mechanistic models of animal behaviour are wrong or inadequate; it is merely to argue that these models cannot encompass all aspects of reality as we know it. Because as valuable as the mechanistic approach is in unravelling physical causation, it simply does not deal with the nature of subjective experience as known and dealt with in daily life. It is therefore a mistake, I suggest, to think that in order to be objective about subjective experience in animals, we must necessarily fit it into a mechanistic approach. Philosophers of language such as Wittgenstein (Hacker, 1993). and more recently Gilbert Ryle in his book The Concept of Mind (Ryle. 19491, have consistently pointed out that to transform subjective states into causal objects is to make a fundamental philosophical and conceptual mistake, also known as 'category mistake'. This is to address a problem in a theoretical perspective which does not reflect the inherent nature of that problem, Subjectivity is not a private sort of object, but a perspective, the experience of 'what-it-is-like-to-be' a particular individual (Sprigge, 197 1; Nagel, 1974. 1986). We should ask what precisely the nature of that experience is, and how we can best, on its own ground, submit it to systematic and reliable investigation. Such an approach may perhaps at first glance appear to clash with the scientific endeavour for strict objectivity. If, however. scientists do wish to assess the experience of living beings, it may well be in their best interest to take the subjective nature of that experience seriously.

\section{Animals as subjects: recognising the integrative, expressive aspects of behavior}

\subsection{The nature of subjective concepts}

In direct interaction with animals we do not primarily treat them as objects. Different members of the public (including scientists) may use animals as instruments for the production of goods such as meat or data, but when actually interacting with animals in a spontaneous, unpremeditated way, they address them as subjects. That is, they use a language which conceives of animals as beings with their own individual perspective on the world, and accordingly, their own needs and desires (Wieder, 1980; Hearne, 1995). We say, for example, that the cat wants to get out of the house, or the pig expects to be fed. The so-called 'lower' animals are included: seeing a fly struggle against a window. we assume it too 'wants' to get out. From such a perspective, a particular animal's behaviour is not conceived as a mechanical system. but as an individual, personal expression, of 'what it may like to be' that animal in a given situation (cf. Sprigge, 1971; Nagel. 1974). This conception is direct, not inferential; we see the behavior displayed in front of us as a perspective, as a subject-related expression, and describe it accordingly.

The notion of 'what-it-is-like-to-be' a certain animal thus reflects an independent, subject-based level of behavioural description and analysis. As such, it does not compete with or replace object-based, mechanistic explanations of behavior, but is complementary to them. To assume that the fly wants to get out does not contradict the assumption that it is attracted by the bright day light; both can be equally true. Nor does it imply that a higher, internal awareness is attributed to the fly, as if the fly 'knew' of its attraction to the light. What this notion does postulate is that behavior, integrally and regardless of its specific cause, matters to an animal in a subjectively involved, experiential sense. The fly does not just show the mere physical motions of struggle, but 'feels' them too; this is why we say it 'wants' to go out (cf. 
Ryle, 1949). This also applies to animals kept in highly restrictive housing conditions, who frequently display a variety of abnormal behaviour patterns. The public at large has become increasingly concerned for the well-being of these animals, and with growing urgency, wonders what it must be like to be a hen in a battery cage, or a chimpanzee in a small laboratory testing pen.

To accept that a subject-based approach constitutes an independent level of description is, however, not to accept anyone's impression at face value. The public's perception of animal suffering must, of course, be submitted to unbiased and reliable investigation. But as argued above, it must be done in a theoretical perspective which reflects the nature of the problem. Current methods of measurement are not designed to describe behaviour in terms of an individual's perspective; they describe behaviour in terms of its constituent physical elements and their causal relationships. Such a methodology, given its very structure, cannot address questions of subjective experience. What is needed is a methodology which, from the start, describes animal behaviour in personal terms, as a perspective, by means of a set of subject-related categories. The question is whether such categories have discriminating power which should be taken seriously in scientific context. It may just be possible that the subject-related terminology which is used in daily life refers to a level of organisation in the behaviour of animals which is real, even if it has so far not been part of scientific analysis. The question to ask then, is what the nature of that level of organisation might be.

\subsection{Animal agency: the voluntary, self-generated nature of behavior}

The primary value of a subject-based approach, I believe, is that it points towards a level of behavioural organisation which cannot be fragmented into underlying causal factors, but which must itself be regarded as fundamental for explanation. This level of organisation reflects what may be called the organism's 'agency'. This notion is not new; it is at the heart of the work of early and influential continental theorists of behaviour such as, amongst many others, Buytendijk (19381, Von UexkllI (19561, and Von Weizs'ricker (1967). The notion of 'agency' asserts that in spontaneous and unpremeditated observation of animals, we do not see just 'behaviour', but, over and above that, what we see is a 'behaver', a dynamic agent. We do not merely see sitting, walking, or licking going on, we see an animal who sits, walks or licks. It is not the legs that walk, or the tongue that licks; it is the animal who walks with its legs or licks with its tongue. Thus, the behaving animal as a whole is not just an emergent by-product of walking legs, licking tongues and wagging tails; it is not merely the sum of the parts. The animal as a whole is the dynamic, integrative centre of action, the very point of origin for any behaviour or movement. This is crucial, in that it opens up another level of description and analysis. It implies that not only can we observe and describe behaviour as an object (i.e. 'the walking'), but also as an expression, a property of a subject (i.e. 'how the animal walks'). The behaving animal is attributed with an individual integrity which cannot be fragmented into constituent mechanical parts, but which becomes the starting-point for the observation of subject-related expressions.

Such a notion of agency, in its emphasis on dynamic integration, implies that behavioural causation is not merely automatic and reactive. The animal appears as the generator of its own movement; movement is perceived as self-movement, as spontaneous and self-generated (i.e. voluntary) in nature. This principle becomes further evident in the dynamic style in which animals interact with the environment. Animals maintain continuous sensory contact with the environment (even during sleep), through processes of attention, orientation and monitoring. Attention is not a by-product of the ability to process information, it forms the very condition for that ability, enabling the animal to use information acquired in the past in a flexible and adaptive manner. The animal's conduct is throughout characterised by active attention for detail, by an active effort to relate to a particular environment and become intimately acquainted with it. Play perhaps is the ultimate manifestation of such diversification. A playing animal may appear unfocused, aimlessly lingering over a particular aspect of the environment, but by indulging in attention as 
an end in itself, it may actually be practising effective agency (Fagen, 1982; see also Wemelsfelder, 1993a for a review of scientific studies indicating the voluntary nature of animal behaviour, including that of invertebrates). Invertebrates may not (as far as we can tell) seem very prone to play, but they do monitor their environment, engage in exploration, and respond flexibly to perceived problems, within the constraints of their species-specific repertoire (for examples see Griffin, 1992).

It seems justified, then, to assert that animals, generally speaking, are generators and evaluators of their own behaviour. The very concepts of monitoring, decision-making and choice imply that animals do not merely have existence as elements of complex reactive causal chains, but are capable of evaluating these chains and directing their course, through processes of attention. Several authors have recognised this ability (although most restrict it to vertebrates), and have given it a central place in their theories of animal welfare (e.g. Wiepkema, 1987; Dawkins, 1990; Wiepkema and Koolhaas, 1993; Toates, this issue). The argument put forward here is basically in line with these theories, but proposes one further, perhaps radical, step: to recognise that this ability makes animals subjects, whose behaviour cannot sufficiently be understood within an exclusively mechanistic conceptual framework. That animals are perceived to be agents, i.e. evaluators of their own behaviour, calls for a theory of causation which explicates the generative and expressive nature of processes of attention. That we have not even begun to understand what it takes to construct such a theory does not make the phenomena of animal and human agency any less real.

The suggestion, however, that principles of causation other than the mechanistic one could exist and operate within the physical universe, frequently meets with disbelief and disapproval within the scientific community. It is felt to violate the principle of parsimony, and to fall outside the rules of scientific explanation (e.g. Kennedy, 1992). Mechanistic explanations are not only seen as adequate, but also as better and more desirable than other kinds of explanation. In this spirit, many scientists take for granted that whatever the properties of behaviour we conceive, it will be possible to built a mechanical robot which simulates those properties convincingly and flawlessly (e.g. Dawkins, 1993).

In response to this contention, several points for debate can be raised. First, there is the general and fundamental issue of the inter-relationship between concept-formation and scientific measurement. Scientists may be suspicious of arguments which, at least partly, depend on conceptual analysis rather than on 'pure' measurement. Thus, they may distrust the argument proposed here, that subject-related phenomena qualitate qua their very nature cannot be assessed in an object-based paradigm. However, no such thing as 'pure' measurement exists; every model of behaviour has a theoretical, and therefore conceptual, basis. Concepts have specific meanings and connotations, and these form a vital part of what constitutes a convincing explanation within a given model. Thus, mechanistic models are not 'neutral', but, as argued above, essentially depend on the notion of reactive causation. They therefore will mould any phenomena they seek to explain into a reactive framework. This may be non-problematic in many cases, but in the case of animal and human agency it is counter-productive. To represent agency as a 'dynamic and integrative mechanism' accomplishes nothing other than solving the problem of subjectivity by conceptually eliminating it. From a scientific view, this is not very interesting. More may be gained by taking up the challenge presented by subject-related concepts: the formulation of a non-mechanistic theory of causation.

On a more practical level as well, the claim that mechanistic accounts can replace subject-based ones is untenable. It is simply inconceivable that scientists could ever rely exclusively on purely mechanistic language in their discussion of animal behaviour. Like the lay public, scientists naturally use, and depend upon, a subject-related terminology to ultimately make sense of their animals' behaviour. There may be tacit agreement that the use of such terms is only a convenient short-hand, and that a purely mechanistic account could be constructed if need be. However, this is an illusion. Despite our tremendously improved 
understanding of neural mechanisms, models of behaviour have remained fundamentally dependent upon agency-related terminology to describe and interpret these mechanisms. Many models, for example, rely on the postulation of monitoring devices such as 'attentional filters', 'comparators' and 'general information processors'. Scientists frequently assume that such attentional mechanisms 'cause' the various forms of behavioural attention (e.g. Sayre, 1986, plus peer commentaries). However, this is unwarranted explanatory reversal. Our conceptual understanding of mechanisms is and remains dependent upon the qualification of an animal's dynamic interaction with the environment. It is therefore meaningless to claim that neural mechanisms 'explain' behaviour; they merely reflect its functional organisation (Bindra, 1984; Searle, 1990). This applies as well to the construction of mechanical robots. The functional design of robotic animals is essentially parasitic upon our understanding of the behaviour of natural animals. That we are able to mechanically imitate animal behaviour does not mean that natural animals must therefore be machines (after Oyama, 1985, p. 163). The claim that mechanical simulation will eventually be flawless, and not distinguishable from the 'real' thing, is entirely speculative and cannot be used as an a priori argument (Meijsing, 1990). It is just as likely that however clever the robot, naive observers will never mistake it for a real animal (contra Dennett, 1991).

Finally, it is not clear why object-based explanations should in principle be more parsimonious than subject-based ones. Occam's razor and Morgan's canon are often brought forward to justify this assumption. However, as Rollin (1989) has pointed out, this seems misguided. Occam's razor says "Do not multiply entities unnecessarily" (cited in Rollin, 1989, p. 75) and objects to postulating too many explanatory units within any given level of explanation, not to postulating different levels of explanation. Morgan's canon states that we should not "interpret an action as the outcome of the exercise of a higher psychical faculty, if it can be interpreted as the outcome of one which stands lower in the psychological scale" (cited in Rollin, 1989, p. 75). This statement obviously accepts a psychological level of explanation in general, but objects, like Occam's razor, to unnecessarily complex explanations within that level (Rollin, 1989). Morgan formulated his canon to point out that the subjective life of animals does not necessarily equal that of humans, but varies along an evolutionary continuum (for a detailed discussion of Morgan's canon and its implications, see Costall, 1993). Thus, there appears to be no general rule dictating that mechanistic explanations per se are more parsimonious than other kinds of explanation.

Subject-based descriptions, then, cannot be replaced by object-based, mechanistic ones. They reflect the voluntary nature of behaviour and as such fulfil an indispensable role in the explanation of behaviour, on every level of organisation. The proposed concept of agency suggests that there is an intrinsic and immediately given relationship between an animal's subjective perspective and the dynamic way in which it attends to and interacts with the environment. The consequence is that, contrary to what is assumed by Cartesian dogma, subjective experience becomes available for empirical observation.

\subsection{Subjective experience as behavioural expression}

A subject-based approach leads to a conception of subjective experience which is not dualistic in the traditional, Cartesian sense of the word. On the highest level of behavioural integration, neither behaviour nor subjective experience can be regarded as objects. Neither one causes the other; they form an integrated, dynamic and expressive whole, the agent. The animal's agency is, as proposed above, primarily manifest in the dynamics of attention and interaction. In the numerous subtle ways in which an animal orients its eyes, ears, nose, whiskers, or its whole body, it shows how it perceives and evaluates the situation it is in. It may withdraw in fear or apprehension, or approach with enthusiasm or anger. To say that an animal 'runs away because it is afraid' then does not refer to a mechanistic causal relationship between fear and running (see previous section), but designates the expression conveyed by the animal's running movements. The animal could have run in many different ways, conveying enthusiasm, exhaustion, or pain. The rendition 'because it is afraid' is thus, despite its non-mechanistic character, not 
trivial; it provides information about the animal's overall state of organisation, and as such has predictive value. Of course one could record the various expressive aspects such as body posture and direction of gaze, in an object-based framework, as if they were 'behaviours' and not properties of a 'behaver'. Indeed one could construct a multi-layered, extremely complex diagram of inter-related and co-dependent attentional parameters. However, in such a scheme, the dynamic centre of action is fragmented into a myriad of separate causal factors. The expressive nature of the animal's actions then becomes an inferential construct, and is inevitably lost as a phenomenon requiring description and analysis in its own right.

A subject-based approach, then, redeems subjective experience from its exclusively private and inaccessible status. This may be counterintuitive in the first instance. Is one's inner world of feeling and experience not uniquely, privately one's own? Such an assumption, in my view, confounds the personal and private nature of subjective experience. That inner experiences are unique and personal in nature does not imply that they are utterly private and inaccessible. That one cannot oneself experience the feelings of another person or animal does not mean that one has no access to the other's feelings at all. In fact, recognising that there is a unique subject out there forms the very basis for attributing experiences to that person (Wittgenstein, as discussed by Hacker, 1993). In the words of the philosopher Thomas Nagel, whose article 'What is it like to be a bat' (1974) acquired world fame: "The point of view in question (i.e. of a bat or any other organism, FW) is not one accessible only to a single individual. Rather it is a type.... One person can know or say of another what the quality of the other's experience is" (Nagel, 1974, p. 396, his italics). Thus, in a subject-based approach, experience retains its open, accessible character. The term 'expression' appropriately reflects this: it indicates that experience is an act, something one actively brings into existence, both for oneself and for others. As such, experience is open to investigation, both by oneself and by others.

\section{Starting-points towards the objective measurement of subjective experience in animals}

But how does one submit subject-related expressions to systematic and reliable investigation? As argued throughout this paper, mechanistic standards of measurement do not apply to a subject-related level of analysis. The question is whether or not it is feasible to develop a methodology which is subject-based in its theoretical starting-points, but which even so can be considered 'objective' in its standards for reliable and repeatable measurement. In the final section of this paper, some starting-points for such a methodology will be put forward for discussion.

A subject-based approach should seek to categorise the dynamics of attention, as manifest in the way in which an animal moves about and relates to its environment (cf. Wemelsfelder, 1993b). What sort of categories should these be? Standard methods of measurement ('ethograms') categorise behaviour in terms of discrete, quantifiable states of physical movement (e.g. walk, sit, chew, sniff). Such categories describe elements of behaviour and their inter-relationships in fine and exact detail. Given their fragmentary nature, however, such categories leave undescribed the dynamic transition between these elements, their integration into a meaningful 'flow' of behaviour. This, it should be clear, is a formal conceptual point; for even highly detailed categories of attention (e.g. body posture, position of ears) could not, as part of a standard ethogram, capture the flow, the expression (see previous section). To complement the static categories of standard ethograms, then, transitional categories are needed. This is exactly how categories of attention, such as enthusiastic, timid, curious or bored, should be understood. Such terms do not refer so much to states, as to styles of behaviour; the term 'style' captures relatively well the dynamic and expressive nature of processes of attention. A subject-based approach, then, may acquire operational status through the categorisation of 'attentional style'. As parameters of behavioural expression, categories of attentional style provide empirical access to the quality of an animal's experience. 
Given their transitional character, categories of attentional style are not liable to standard procedures of quantification. It is not possible to score an animal's attentional style from moment to moment, in linear fashion, as one would score categories of physical movement. An animal is not curious the one moment and timid the next. Attentional style unfolds, becomes apparent, as time proceeds; it is necessary to observe behaviour over a certain period of time before its dynamic qualities become evident. A variety of behaviour patterns, performed in various contexts over a prolonged period of time, can all be part of a particular style or expression. To name the quality of an animal's experience, therefore, is to choose a concept which adequately summarises and integrates the emerging dynamic order. Such a procedure of categorisation, as will be clear, inevitably involves qualitative linguistic judgement on the part of the observer. The observer must decide which category best designates the sum-total of all momentary observations; a decision which cannot be based on rigid, pre-determined standards, but must rely on qualitative assessment. Categorisation of attentional style therefore can facilitate the measurement of subjective experience, but only if the scientific validity of qualitative assessment is accepted.

An obstacle for such acceptance may be that qualitative assessment is readily dismissed as 'anthropomorphic'. And indeed, this kind of assessment demands a more active interpretative role of the observer than is the case with quantitative ethograms. However, rather than dismiss this active role as unscientific, perhaps we should seek to understand and formalise it. Human observers, as agents, may well be capable of accessing a level of information which, given its dynamic variability and subtlety, evaporates within object-based methods of measurement (cf. Van Praag, 1992). The task ahead is to design, with the help of well-trained human observers, a terminology which adequately captures the expressive repertoire of various animal species. To this end, larger groups of observers should be asked to assign categories of attentional style to individual animals, under carefully controlled experimental conditions. A variety of statistical methods is available to test whether or not these assignments have trans-personal validity, and show intra- and inter-observer reliability (e.g. Streiner, 1993; Tyrer et al., 1993). If satisfactory reliability can be established, it follows that the qualitative assessment of behaviour can be submitted to systematic and repeatable procedures of measurement. This should be sufficient to endow a subject-based approach of animal behaviour, despite its non-mechanistic character, with objective, scientific status.

Starting-points for such an approach can already be found in various scientific disciplines. For example, categories of attentional style are frequently used in rating scales designed to classify different forms of human depression (e.g. Parker et al., 1990). Studies of human depression tend not to regard depression as a singular state, but rather as a dynamic syndrome, manifest in a large variety of signs and symptoms (Snaith, 1993). The categories 'retardation' and 'agitation', indicating contrasting types of psychomotor disturbance, play a prominent role in attempts to summarise and interpret these signs (Parker et al., 1994). Qualifications of behavioural style such as these seem to be gaining increasing importance in the study of human mental health; the study of animal well-being and suffering may well benefit from methodological experience gained in this field. Furthermore, qualitative rating scales have been applied successfully in the study of personality traits in cats and various primates (Buirski et al., 1973; StevensonHinde and Zunz, 1978; Buirski et al., 1978; Stevenson-Hinde et al., 1980; Feaver et al., 1986; Gold and Maple, 1994). Mend1 and Harcourt (1988) note that personality traits such as 'curious' and 'active' refer to complex, emergent patterns of behaviour which remain elusive within standard recording methods. They do not discuss, however, whether for this reason personality traits may be seen as subject-related qualifications of behaviour. Nevertheless, the increasing number of studies on individual differences within various animal species (including the Octopus, Mather and Anderson, 1993) indicate a growing willingness to recognise the active role of the individual animal in regulating its interaction with the environment. From such various angles, an interest in the development of new methodologies may 
converge, stimulating a more qualitative approach towards animal behaviour. This paper hopes to have contributed towards that goal.

\section{Acknowledgements}

I would like to thank Alistair Lawrence, Mike Mendl, Fred Toates and four anonymous referees for helpful comments on an earlier version of this paper. The financial support for this work provided by MAFF (proj.m. CSA 2870 is gratefully acknowledged.

\section{References}

Bekoff, M., 1994. Cognitive ethology and the treatment of non-human animals: how matters of mind inform matters of animal welfare. Anim. Welfare, 3: 75-96.

Bindra, D., 1984. Cognition, its origin and future in psychology. In: J.R. Royce and L.P. Mos (Editors), Annals of Theoretical Psychology. Plenum Press, New York, pp. I-29.

Buirski, P., Kellerman, H., Plutchik, R. and Weininger, R., 1973. A field study of emotions, dominance, and social behavior in a group of baboons (Papio anubis). Primates, 14: 67-78.

Buirski, P., Plutchik, R. and Kellerman, H., 1978. Sex differences, dominance and personality in the chimpanzee. Anim. Behav., 26: 123-129.

Buytendijk, F.J.J., 1938. Grondproblemen van het dierlijk leven. N.V. Dekker and Van Devegt, Nijmegen.

Costall, A., 1993. How Lloyd Morgan's canon backfired. J. Hist. Behav. Sci., 29: 113-122.

Dawkins, MS., 1990. From an animal's point of view: motivation, fitness, and animal welfare. Behav. Brain Sci., 13: I-61.

Dawkins, M.S., 1993. Through our Eyes Only? The Search for Animal Consciousness. W.H. Freeman, Oxford.

Dennett, D.C., 1991. Consciousness Explained. Little, Brown \& Company, Boston.

Dickinson, A., 1985. Actions and habits: the development of behavioural autonomy. Phil. Trans. R. Sot. London, Ser. B, 308: 67-78.

Duncan, I.J.H. and Petherick, J.C., 1991. The implications of cognitive processes for animal welfare. J. Anim. Sci., 69: 5017-5022.

Fagen, R., 1982. Evolutionary issues in the development of behavioral flexibility. In: P.P.G. Bateson and P.H. Klopfer (Editors), Perspectives in Ethology 5. Plenum Press, New York, pp. 365-383.

Feaver, J., Mendl, M. and Bateson, P., 1986. A method for rating the individual distinctiveness of domestic cats. Anim. Behav., 34: 1016-1025.

Gold. K.C. and Maple. T.L., 1994. Personality assessment in the Gorilla and its utility as a management tool. Zoo Biol., 13: 509-522.

Griffin. D.R., 1992. Animal Minds, University of Chicago Press. Chicago.

Hacker, P.M.S., 1993. Wittgenstein: meaning and mind. Part I. Essays. Blackwell. Oxford.

Hearne. V.. 1995. Animal Happiness. HarperPerennial. New York.

Heyes. C.. 1993. Anecdotes. training. trapping and triangulating: do animals attribute mental states'? Anim. Behav.. 46: 177- 188.

Heyes, C.. 1994. Reflections on self-recognition in primates. Anim. Behav.. 47: 909-919.

Kennedy. J.S.. 1992. The New Anthropomorphism. Cambridge University Press. Cambridge.

Marher. J.A. and Anderson, R.C., 1993. Personalities of Octopuses (Octopus ruhescrm). J. Comp. Psycho].. 107: 336-340.

McFarland. D.. 1989. Problems of Animal Behaviour. Longman, Scientific and Technical, Burnt Mill. UK. 
Meijsinf. M.. 1990. Mens of Machine'? Het lichaam-geest probleem in de cognitieve prychologie, 2e druk. Swets and Zeitlinger. Amsterdam.

Mendl. M. and Harcourt. R.. 1988. Individuality in the domestic cat. In: D.C. Turner and P.P.G. Bateson (Editors). The Domestic Cat: the Biology of its Behaviour. Cambridge University Press. Cambridge. pp. 11-53.

Nagel. T.. 1973. What is it like to be a bat? Psychol. Rev.. 83: 435-451.

Nagel. T.. 1986. The View from Nowhere. Oxford University Press, Oxford.

Oyama. S.. 19X5. The Ontogeny of Information. Cambridge University Press. Cambridge.

Parker. G., Hadzi-Pavlovic. D.. Boyce. P.. Wilhelm, K., Brodaty. H.. Mitchell, P.. Hickie. I. and Eyers. K.. 1990. Classifying depression by mental state signs. Br. J. Psychiat.. 157: 55-65.

Parker. G.. Hadzi-Pavlovic. Wilhelm. K.. Hickie, I., Brodaty. H.. Boyce. P., Mitchell. P. and Eyers. K.. 1994. Defining melancholia: properties of a refined sign-based measure. Br. J. Psychiat.. 164: 3 16-326.

Rollin. B.E.. 1989. The Unheeded Cry. Animal Consciousness. Animal Pain and Science. Oxford University Press. Oxford.

Rushen. J., 1984/85. The scientific status of animal consciousness. Appl. Anim. Behav. Sci.. 387-390.

Ryle. G.. 1949. The Concept of Mind. Penguin, Harmondsworth, UK.

Sayre. K.M., 1986. Intentionality and information processing: an alternative model for cognitive science. Behav. Brain Sci.. 9: 121-166.

Searle. J.R.. 1990. Consciousness. explanatory inversion. and cognitive science. Behav. Brain Sci.. 13: S85-642.

Snaith. P.. 1993. What do depression rating scales measure? Br. J. Psychiat.. 163: 293-298.

Sprigge. T.L.S., 1971. Final Causes. The Aristotelian Society Supplementary Volume XLV. pp. 149- 170.

Staddon. J.E.R.. 1983. Adaptive Behavior and Learning. Cambridge University Press, Cambridge.

Stevenson-Hinde. J. and Zunz. M.. 1978. Subjective assessment of individual rhesus-monkeys. Primates, 19: 373-482.

Stevenson-Hinde, J.. Stillwell-Barnes, R. and Zunz. M.. 1980. Subjective assessment of rhesus monkeys over four successive years, Primates. 21 : 66-82.

Streiner. D.L.. 1993. A checklist for evaluating the usefulness of rating scales. Can. J. Psychiat., 38: 140148.

Tinbergen. N.. 1989. The Study of Instinct [originally published: 19511. Clarendon Press, Oxford. p. 5.

Tyrer. P.. Henderson. F. and McDermott, U.. 1993. Validation of rating scales in psychiatry. Br. J. Hosp. Med.. 49: 434-437.

Van Praag. H.M.. 1992. Reconquest of the subjective; against the waning of psychiatric diagnosing, Br. J. Pcychiat.. 160: 266-271.

Van Rooijen. J , 1983. Awareness and Griffin's circular reasoning. Anim. Behav., 31: 613-614.

Van Rooijen. J.. 1991. The value of a philosophical fundament for animal welfare research. Appl. Anim. Behav. Sci.. 28: 387-388.

Van Uexkiill. J.. 1956. Streifziige durch die Umwelten von Tieren und Menlchen. Rowohlt. Hamburg.

Van Weizsscker. V., 1967. Der Gestaltkreir. 4th edn. Stuttgart.

Wemelsfelder. F.. 1993a. Animal boredom: towards an empirical approach of animal subjectivity. Elinkwijk. Utrecht. Available through the author,

Wemelsfelder. F.. 1993b. The concept of animal boredom and its relationship to stereotyped behaviour. In: A.B. Lawrence and J. Rushen (Editors), Stereotypic Animal Behaviour: Fundamentals and Applications to Animal Welfare. CAB International, Wallingford, UK, pp. 65-95.

Wieder, D.L., 1980. Behavioristic operationalism and the life-world: chimpanzees and chimpanzee researchers in face-to-face interaction. Social. Inquiry, 50: 75-103. 
Wiepkema, P.R., 1987. Behavioural aspects of stress. In: P.R. Wiepkema and P.W.M. van Adrichem (Editors), Biology of Stress in Farm Animals: an Integrative Approach. Martinus Nijhoff, Dordrecht, pp. 113-133.

Wiepkema, P.R. and Koolhaas, J.M., 1993. Stress and animal welfare. Anim. Welfare, 2: 195-218. 